\title{
Solar Photocatalytic Removal of Chemical and Bacterial Pollutants from Water Using $\mathrm{Pt} / \mathrm{TiO}_{2}$-Coated Ceramic Tiles
}

\author{
S. P. Devipriya, ${ }^{1,2}$ Suguna Yesodharan, ${ }^{1}$ and E. P. Yesodharan ${ }^{1}$ \\ ${ }^{1}$ School of Environmental Studies, Cochin University of Science and Technology, Kochi 682022, India \\ ${ }^{2}$ Department of Ecology and Environmental Sciences, Pondicherry University, Puducherry 605014, India \\ Correspondence should be addressed to E. P. Yesodharan, epyesodharan@gmail.com
}

Received 24 January 2012; Revised 22 March 2012; Accepted 27 March 2012

Academic Editor: Baibiao Huang

Copyright ( $) 2012$ S. P. Devipriya et al. This is an open access article distributed under the Creative Commons Attribution License, which permits unrestricted use, distribution, and reproduction in any medium, provided the original work is properly cited.

\begin{abstract}
Semiconductor photocatalysis has become an increasingly promising technology in environmental wastewater treatment. The present work reports a simple technique for the preparation of platinum-deposited $\mathrm{TiO}_{2}$ catalysts and its immobilization on ordinary ceramic tiles. The $\mathrm{Pt} / \mathrm{TiO}_{2}$ is characterized by X-ray diffraction (XRD), scanning electron microscopy (SEM), energy dispersive X-ray spectroscopy (EDAX), and diffuse reflectance spectroscopy (DRS). Deposition of Pt on $\mathrm{TiO}_{2}$ extends the optical absorption of the latter to the visible region which makes it attractive for solar energy application. Optimum loading of Pt on $\mathrm{TiO}_{2}$ was found to be $0.5 \%$. The $\mathrm{Pt} / \mathrm{TiO}_{2}$ is coated on ceramic tiles and immobilized. This catalyst was found effective for the solar photocatalytic removal of chemical and bacterial pollutants from water. Once the parameters are optimized, the $\mathrm{Pt} / \mathrm{TiO}{ }_{2} / \mathrm{tile} \mathrm{can}$ find application in swimming pools, hospitals, water theme parks, and even industries for the decontamination of water.
\end{abstract}

\section{Introduction}

Semiconductor-mediated photocatalysis is fast becoming an efficient advanced oxidation process (AOP) for the removal of chemical and bacterial pollutants from water [1-5]. The most widely studied catalyst in this respect is $\mathrm{TiO}_{2}$ in view of its favorable physicochemical properties, low cost, easy availability, high stability, and low toxicity. However, it is active only in the UV range which constitutes less than $5 \%$ of sunlight. Photocatalytic reactions take place when particles of the semiconductor absorb photon of energy equal to or greater than its band gap and the electrons get excited from the valence band to the conduction band. This results in the formation of an electron-hole pair which promotes oxidation/reduction of the adsorbed substrate. In aqueous solution, the reactive $\mathrm{OH}$ radicals can promote the oxidation and eventual mineralization of organic compounds.

A number of studies have been reported on the modification of semiconductor oxides in order to extend the absorption of light to the visible range. These include dye sensitization, semiconductor coupling, impurity doping, use of coordination metal complexes, and metal deposition [6-18]. Composites such as $\mathrm{TiO}_{2} /$ carbon have also been reported [19-21]. Deposition of noble metals such as Pt, Pd, $\mathrm{Au}$, and $\mathrm{Ag}$, on $\mathrm{TiO}_{2}$ enhances the catalytic oxidation of organic pollutants [22-26].

$\mathrm{Pt} / \mathrm{TiO}_{2}$ nanocomposites have been shown to have high photocatalytic activity for the decomposition of organic compounds. In this case, the enhancement is attributed to the increased light absorption and retarding of the photogenerated electron-hole recombination [25-27]. However, since $\mathrm{Pt}$ is expensive, this type of catalysts will be unattractive from commercial application point of view unless they can be recycled. The problem can be overcome, at least partially by immobilizing the catalyst on suitable stable supports.

It is reported that nanoparticles of noble metals such as $\mathrm{Au}, \mathrm{Ag}$, and $\mathrm{Pt}$ are capable of absorbing visible light due to the surface plasmon resonance (SPR) in which their conducting electrons undergo a collective oscillation induced by the electric field of visible light [28-30]. Ag and Au nanoparticles supported on insulators such as $\mathrm{ZrO}_{2}$ and $\mathrm{SiO}_{2}$ yield visible light active photocatalysts capable of promoting both oxidative and reductive reactions [31,32]. Zheng et al. [28] have recently reported a facile in situ synthesis of visible light plasmonic photocatalysts $\mathrm{M}-\mathrm{TiO}_{2}(\mathrm{M}=\mathrm{Au}, \mathrm{Pt}, \mathrm{Ag})$ and their evaluation for the oxidation of benzene to phenol in aqueous 
phenol. Other efficient and stable plasmonic catalysts such as $\mathrm{Ag} / \mathrm{AgCl}[33]$ and $\mathrm{Ag} / \mathrm{AgBr} / \mathrm{WO}_{3} \cdot \mathrm{H}_{2} \mathrm{O}$ [34] are also reported. In such catalysts, visible light is absorbed by nanoparticles of the noble metal, and the photogenerated electrons and holes are separated by the metal-semiconductor interface. Thus, the electron-hole recombination is prevented, and the photocatalytic process is accelerated. In the case of $\mathrm{Au} / \mathrm{TiO}_{2}$ plasmonic photocatalysts, the mechanism of visible-lightinduced photocatalytic oxidation involves the absorption of light by $\mathrm{Au}$ nanoparticles which causes electron transfer from them to the conduction band of $\mathrm{TiO}_{2}$ particles. Consequently, the oxidation of the organics will take place at the electron-deficient Au nanoparticles [28].

In the present study, we have immobilized $\mathrm{Pt} / \mathrm{TiO}_{2}$ on a ceramic tile in order to enhance the commercial viability of the catalyst by recycling. The photocatalytic activity of this catalyst is tested for the removal of a typical chemical pollutant dye Rhodamine B and a bacterial pollutant E. coli.

\section{Experimental}

Degussa P-25 $\mathrm{TiO}_{2}$ is used as such without further treatment. It is $99 \%$ pure and consisted of approximately $70 \%$ anatase and $30 \%$ rutile forms. The average particle size was around $200 \mathrm{~nm}$, and the BET surface area was $\sim 15 \mathrm{~m}^{2} / \mathrm{g}$. Analytical grade chloroplatinic acid $\left(\mathrm{H}_{2} \mathrm{PtCl}_{6} \cdot 6 \mathrm{H}_{2} \mathrm{O}\right)$ and Rhodamine $\mathrm{B}$ were from Sigma-Aldrich, India. All other chemicals used were of AR grade. Doubly distilled water was used in all the experiments. The immobilized $\mathrm{Pt} / \mathrm{TiO}_{2}$ photocatalyst $\left(\mathrm{Pt} / \mathrm{TiO}_{2} /\right.$ tile $)$ is prepared as follows [26].

Aqueous suspension containing specific quantity of Degussa P-25 $\mathrm{TiO}_{2}$ was taken in the photoreactor and purged with nitrogen to remove dissolved oxygen. Specified amounts of $\mathrm{H}_{2} \mathrm{PtCl}_{6} \cdot 6 \mathrm{H}_{2} \mathrm{O}$ dissolved in $20 \mathrm{~mL}$ methanol were then added to the aqueous suspension of $\mathrm{TiO}_{2}$ and agitated with a magnetic stirrer. The suspension under nitrogen atmosphere is then irradiated with $400 \mathrm{~W}$ UV lamp for $8 \mathrm{hr}$. The milky white suspension turns grayish with the deposition of Pt. The suspension is then filtered, and after repeated washings with doubly distilled water, it is dried and powdered.

Common glazed tiles normally used for flooring are etched with dilute HF. The surface is then cleaned and coated uniformly with the paste of $\mathrm{Pt} / \mathrm{TiO}_{2}$ and polymethyl methacrylate in chloroform. The tile is then dried at $110^{\circ} \mathrm{C}$ and later heated at $350^{\circ} \mathrm{C}$ for $3 \mathrm{hr}$. A thin film of $\mathrm{Pt} / \mathrm{TiO}_{2}$ is formed on the surface of the tile. For control experiments, tiles were prepared exactly as above, one with $\mathrm{TiO}_{2}$ only and another without any catalyst. The amount of catalyst coated was determined by measuring the weight difference of the tile before and after the coating.

X-ray diffraction pattern of the coated catalyst is determined by using Rigaku X-ray diffractometer with CuKó radiation. Scanning electron microscopy (SEM) measurements were performed with JEOL Model JSM-6390 LV. Energy dispersive X-ray spectroscopy (EDAX) measurements were made using JOEL model JED-2300 attached to SEM. Diffuse reflectance spectra (DRS) were recorded with Varian Cary 5000 using $\mathrm{BaSO}_{4}$ as the reference.
Photocatalytic experiments with dye solution were performed as follows.

The coated tile $(12 \times 8 \times 0.5 \mathrm{~cm})$ is placed in a jacketed glass vessel of approximately $20 \mathrm{~cm}$ diameter and $3 \mathrm{~cm}$ height. The experimental dye solution of Rhodamine $\mathrm{B}$ $(200 \mathrm{~mL}, 10 \mathrm{mg} / \mathrm{L})$ is slowly added into the vessel. Water from a thermostat is circulated through the jacket to maintain the temperature at $27 \pm 1^{\circ} \mathrm{C}$. For UV experiments, the dye solution is irradiated with a $400 \mathrm{~W}$ medium pressure mercury vapor lamp. Solar experiments were performed by placing the same system on the roof top of our laboratory at Kochi, Kerala, India ( $\left.9^{\circ} 57^{\prime} 51^{\prime \prime} \mathrm{N}, 76^{\circ} 16^{\prime} 59^{\prime \prime} \mathrm{E}\right)$ during sunny days in February-May 2010. Periodically, the dye solution is mixed gently. Samples were drawn periodically and analyzed for the dye concentration by spectrophotometry (555 nm). Solution kept under identical conditions in the dark is used as the reference in each case to eliminate the contribution from adsorption towards the reduction in the dye concentration.

For bacterial disinfection studies, Escherichia coli (ATCC 11775 ) was used as the test organism. Cells of E. coli were subcultured under sterile conditions at $37^{\circ} \mathrm{C}$ for $24 \mathrm{hr}$ in $100 \mathrm{~mL}$ nutrient broth ( $\mathrm{pH} \sim 7.2$ ) containing $0.1 \mathrm{~g}$ of yeast extract, $0.5 \mathrm{~g}$ of peptone, and $0.5 \mathrm{~g}$ of $\mathrm{NaCl}$. The cells were sedimented by centrifugation at $5000 \mathrm{rpm}$ for 10 minutes, washed, and resuspended in sterile distilled water. Absorbance was measured using Shimadzu UV-1601 UV-VIS spectrophotometer. Cell cultures corresponding to $\sim 10^{7}$ cells $/ \mathrm{mL}$ were used to inoculate the reaction systems and controls. Control experiments run in parallel consisted of samples exposed to sunlight without catalyst and those in the dark with and without catalysts, all maintained under otherwise identical conditions. In catalytic experiments, the coated tiles were placed in aquarium jars containing 10 liters of the inoculated water. The jars were placed in a trough through which water at the required temperature is circulated and irradiated by sunlight. Sampling was done at predetermined intervals by pipetting out $1 \mathrm{~mL}$ of the experimental solution into $9 \mathrm{~mL}$ sterile saline which was serially diluted. After mixing, $0.1 \mathrm{~mL}$ aliquots of each dilution were spread onto McConkey agar plates. The cell inactivation was monitored by counting the colony forming units (CFU) after 24-hour incubation at $37^{\circ} \mathrm{C}$.

\section{Results and Discussions}

3.1. Surface Characterization of the Photocatalyst. The photo deposition of Platinum on the $\mathrm{TiO}_{2}$ surface was indicated by color change of the particles from white to grey. XRD analysis is done to study the phase structure of the catalyst. Figure 1 shows characteristic peaks of $\mathrm{TiO}_{2}$ only with no indication of the presence of $\mathrm{Pt}$. This may be because either $\mathrm{Pt}$ is not getting deposited on $\mathrm{TiO}_{2}$ or the concentration of $\mathrm{Pt}$ in the $\mathrm{TiO}_{2}$ matrix is too small to be detected by XRD. As the results presented later in this paper show, reflectance spectrum and enhanced photocatalytic activity of the prepared material reveal modification in the properties of $\mathrm{TiO}_{2}$, which can be attributed to the presence of small amounts of highly dispersed Pt. Scanning electron microscopy (SEM) of 


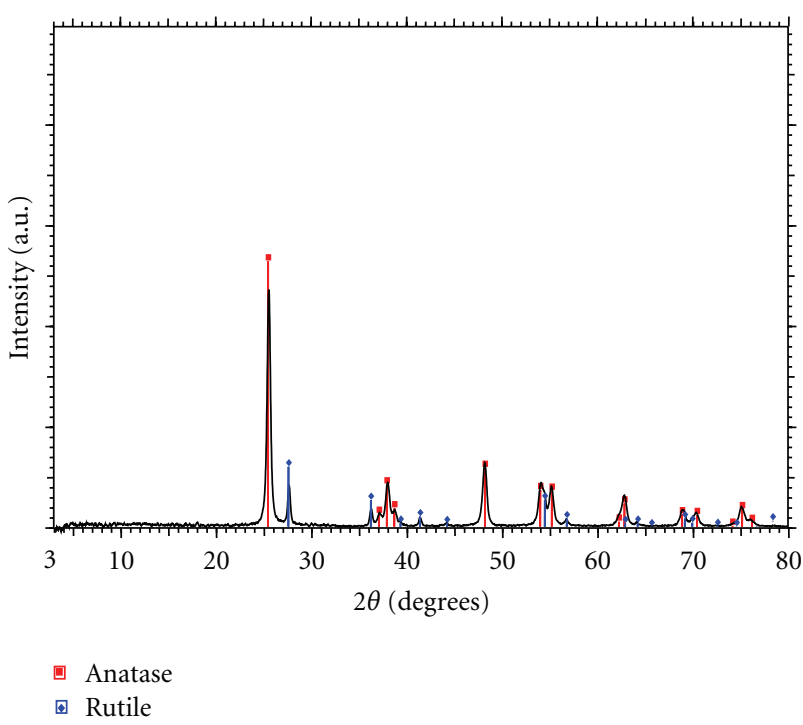

FIGURE 1: XRD pattern $\mathrm{Pt} / \mathrm{TiO}_{2}$ coated on the surface of the ceramic tile.

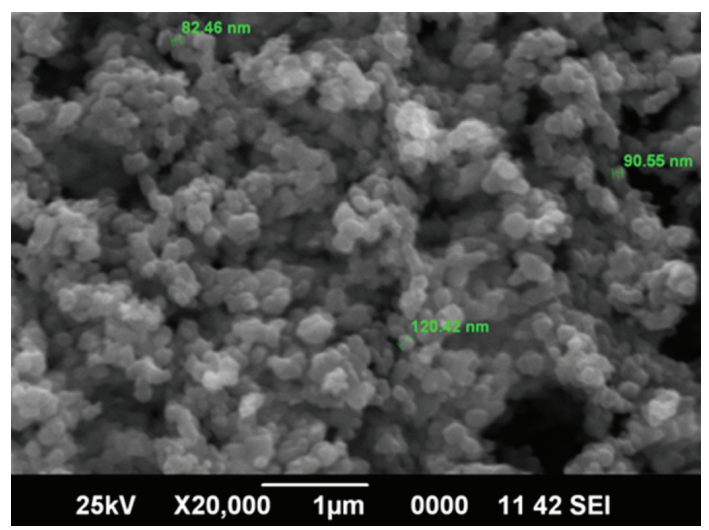

Figure 2: SEM of Pt $(0.5 \mathrm{wt} \%)$-deposited on $\mathrm{TiO}_{2}$.

the sample with 0.5 weight $\%$ of $\mathrm{Pt}$ dispersed on $\mathrm{TiO}_{2}$ (Figure 2) shows that the particles are approximately spherical in nature. Elemental mapping of Pt by EDAX (Figure 3) shows that the metal particles are uniformly distributed on the surface of $\mathrm{TiO}_{2}$, even though the characteristic peaks are not quite distinct possibly due to the very low concentration of Pt.

The DRS spectrum of the $\mathrm{Pt} / \mathrm{TiO}_{2}$ sample shown in Figure 4 indicates that the optical absorption of $\mathrm{TiO}_{2}$ is enhanced significantly from $360 \mathrm{~nm}$ onwards. This extension towards the visible region of the optical spectrum is consistent with the findings reported by earlier investigators $[25,26]$.

According to F. B. Li and X. Z. Li [25] and Chen et al. [26], deposition of $\mathrm{Pt}$ on $\mathrm{TiO}_{2}$ results in the formation of $\mathrm{Ti}^{3+}$, possibly due to the interaction between $\mathrm{Pt}$ and $\mathrm{TiO}_{2}$ during photo reduction. The presence of $\mathrm{Ti}^{3+}$ sites in the lattice may form a defect energy level in the band gap of $\mathrm{TiO}_{2}$ thereby absorbing visible light more efficiently and resulting in enhanced photocatalytic activity. The dispersion of $\mathrm{Pt}$

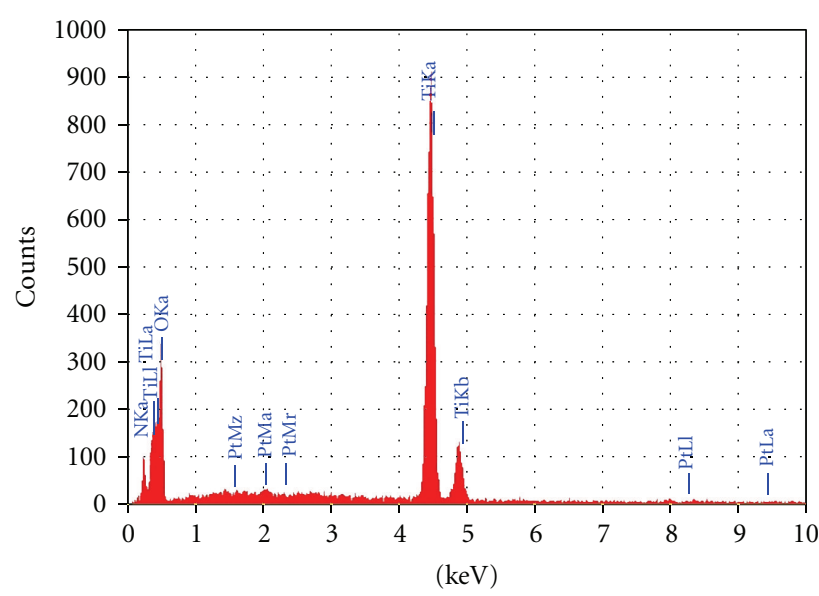

Figure 3: EDAX spectrum of $\mathrm{Pt} / \mathrm{TiO}_{2}$.

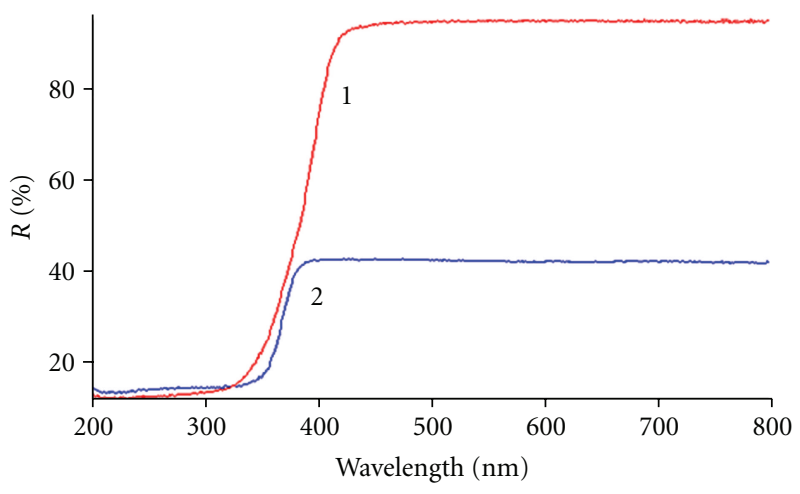

Figure 4: DRS spectra of (1) $\mathrm{TiO}_{2}(\mathrm{P}-25)$ and (2) $\mathrm{Pt} / \mathrm{TiO}_{2}$.

nanoparticles in the $\mathrm{TiO}_{2}$ matrix can also produce some energy levels in the band gap of the latter [25]. Sakthivel et al. [23] also concluded from similar studies that defect sites on the $\mathrm{TiO}_{2}$ surface, identified as $\mathrm{Ti}^{3+}$, are necessary for adsorption and photoactivation of oxygen which are the primary steps in photocatalysis. In the present case, the deposition of $\mathrm{Pt}$ was made in the absence of air. Hence, the in situ transformation of $\mathrm{Ti}^{3+}$ to $\mathrm{Ti}^{4+}$ by oxygen can be ruled out. However, in presence of the platinum salt, the photogenerated $\mathrm{Ti}^{3+}$ ions reduce the noble metal cations to neutral $\mathrm{Pt}$ atoms. These atoms can nucleate to grow into clusters, eventually forming nanoparticles of $\mathrm{Pt}$ on the $\mathrm{TiO}_{2}$ surface $\left(\mathrm{Pt} / \mathrm{TiO}_{2}\right)$. The surface plasmon resonance in $\mathrm{Pt} / \mathrm{TiO}_{2}$ under visible light irradiation enables the transfer of photogenerated electrons from the metal particles to $\mathrm{TiO}_{2}$ conduction band by crossing the metal-semiconductor interface and surmounting the Schottky barrier [28]. This will reduce the recombination of the electron-hole pair. The electrons are taken up by adsorbed oxygen forming active species which interact with the organic substrate, leading to eventual mineralisation. In the process, the substrate can compensate the depleted electron, and the SPR is fully restored, thereby ensuring continued efficient photocatalytic activity. 

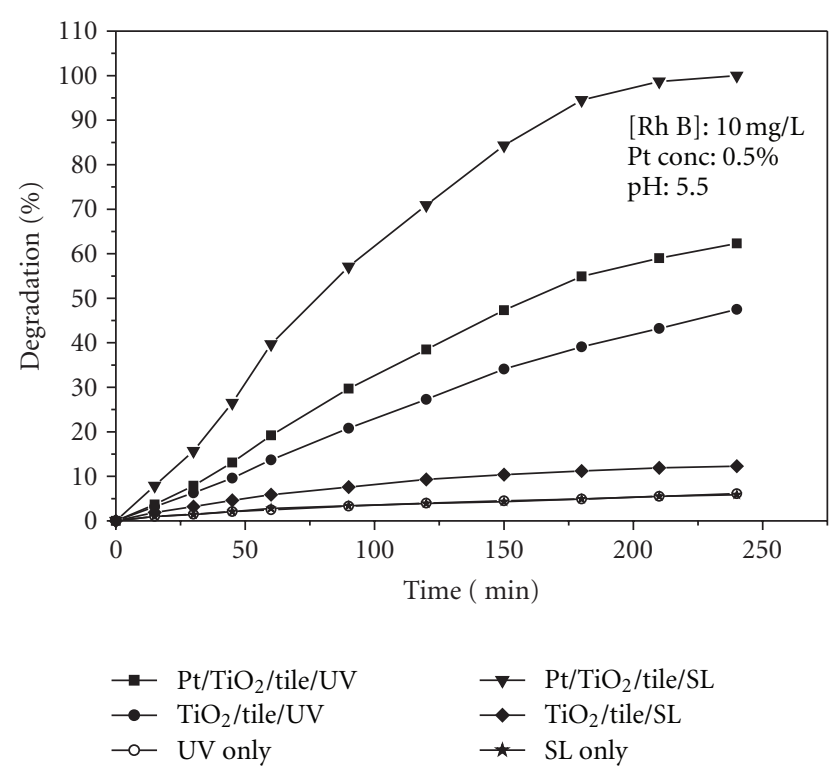

Figure 5: Photocatalytic degradation of Rhodamine B under various conditions in presence of UV and sunlight (SL).

3.2. Photocatalytic Degradation of Rhodamine B on $\mathrm{Pt} / \mathrm{TiO}_{2}-$ Coated Tiles. Photocatalytic degradation of the highly soluble basic red dye of the xanthenes class, Rhodamine $\mathrm{B}$, is evaluated using $\mathrm{TiO}_{2} /$ tile and $\mathrm{Pt} / \mathrm{TiO}_{2} /$ tile. Earlier studies reported on the degradation of the dye involved the use of catalyst suspensions, which are not quite convenient in terms of practical application. The advantage of the immobilized catalyst over suspension is that it needs not be separated from water every time and can be recycled. Degradation of the dye takes place even in the absence of catalyst, though slowly. The degradation is investigated in both UV light as well as in sunlight (SL). The $\mathrm{pH}$ of the system is maintained at 5.5 which is close to the natural $\mathrm{pH}$ of the dye solution under the reaction conditions used in the study. The results are plotted in Figure 5.

As expected, $\mathrm{Pt} / \mathrm{TiO}_{2}$ is more active in the visible sunlight as well as in the UV region compared to $\mathrm{TiO}_{2}$. Degradation/decolorisation in the absence of catalysts may be due to the natural self-fading of the dye.

The percentage degradation of the dye in presence of $\mathrm{Pt} / \mathrm{TiO}_{2} /$ tile is about $60 \%$ more compared to $\mathrm{TiO}_{2} /$ tile under UV irradiation. However, the degradation is approximately 5 times more in the case of $\mathrm{Pt} / \mathrm{TiO}_{2} /$ tile compared to $\mathrm{TiO}_{2} /$ tile in presence of sunlight. The comparative enhancement in this case increases as the irradiation progresses, possibly due to the inability of pure $\mathrm{TiO}_{2}$ to get activated significantly in sunlight. At the same time, Pt nanoparticles absorb visible light resulting in the formation of electron-hole pairs and subsequent activation of adsorbed oxygen as explained earlier. The superoxide/hydroperoxide $\left(\mathrm{O}_{2}{ }^{-} / \mathrm{HO}_{2}{ }^{\bullet}\right)$ radicals thus formed initiate degradation of the dye. Repeated attacks by the $\left(\mathrm{O}_{2}{ }^{-\bullet} / \mathrm{HO}_{2}{ }^{\bullet}\right)$ radicals on the dye nuclei will lead to mineralization producing mainly $\mathrm{CO}_{2}$ and water.

$$
\mathrm{Pt}-\mathrm{TiO}_{2}\left(e_{\mathrm{CB}}{ }^{-}\right)+\mathrm{O}_{2} \longrightarrow \mathrm{O}_{2}{ }^{-\bullet}
$$

$$
\mathrm{O}_{2}{ }^{-\bullet}+\text { Dye } \longrightarrow \text { Intermediates } \longrightarrow \text { Degradation products }
$$

In the case of pure $\mathrm{TiO}_{2}$ also, the degradation of the dye is significant in sunlight unlike in the case of substrates like phenol, alcohol, cresol, and so forth where the degradation is much slower [35]. This might be because the dye Rhodamine B can absorb visible light and act as a sensitizer thereby transferring electrons from the excited dye molecule to the conduction band of $\mathrm{TiO}_{2}$,

$$
\begin{gathered}
\operatorname{Dye}_{(\mathrm{ads})} \longrightarrow \mathrm{Dye}_{(\mathrm{ads})}{ }^{*} \\
\mathrm{Dye}_{(\mathrm{ads})}{ }^{+}+\mathrm{Pt}^{-} \mathrm{TiO}_{2} \longrightarrow \mathrm{Dye}_{(\mathrm{ads})}{ }^{+}+\mathrm{Pt}_{-} \mathrm{TiO}_{2}\left(e_{\mathrm{CB}}{ }^{-}\right) \\
\mathrm{Dye}_{(\mathrm{ads})}{ }^{+} \longrightarrow \text { Intermediates } \longrightarrow \text { Oxidation/Degradation }
\end{gathered}
$$

The electrons are scavenged by the oxygen adsorbed on the surface of $\mathrm{TiO}_{2}$ as in (1) above. Thus, the dye behaves like an electron donor at the excited state and injects electron directly to the conduction band upon irradiation. Anandan et al. [36] also suggested similar pathway for the degradation of dyes on $\mathrm{Ag} / \mathrm{TiO}_{2}$ catalysts.

The study further shows that, in the presence of sunlight, the photocatalytic activity of dye sensitized $\mathrm{TiO}_{2}$ is much less compared to $\mathrm{Pt} / \mathrm{TiO}_{2}$. Deposition of $\mathrm{Pt}$ enhances the photocatalytic activity of $\mathrm{TiO}_{2}$ in two ways, that is, by the prevention of electron hole recombination and the extension of the light absorption range as discussed earlier. Modification of the surface of $\mathrm{TiO}_{2}$ by Pt can also result in enhancement of the number of active sites for the dye-catalyst interaction which in turn can increase the photodegradation rate. On the other hand, dye sensitization of $\mathrm{TiO}_{2}$ leads to only visiblelight absorption which is highly concentration dependent. At lower concentration, when there is only monolayer coverage of the dye, light absorption may not be adequate to acquire sufficient energy to be transferred to the semiconductor. At the same time, multilayer adsorption of the dye does not enhance the light absorption or photocatalytic efficiency significantly because the inner layers will tend to act as insulators with respect to outer layers [37].

The effect of concentration of $\mathrm{Pt}$ in $\mathrm{Pt} / \mathrm{TiO}_{2}$ on the rate of degradation of the dye is tested by varying the loading of the former in $\mathrm{TiO}_{2}$, that is, $0.1,0.25,0.75$, and $1.0 \%$. The rate constant of degradation in sunlight at various Pt concentrations is plotted in Figure 6. The rate increases with Pt loading initially. However, it levels off or even decreases slightly beyond the optimum.

The detrimental effect of higher content of Pt in photocatalytic degradation was reported earlier also [25]. At lower concentration, Pt clusters can act as charge separation centres. As explained earlier, one of the reasons for the enhanced photocatalytic activity of $\mathrm{Pt} / \mathrm{TiO}_{2}$ is the separation of the photogenerated electrons and holes by the metal-semiconductor interface which prevents their recombination. However, at higher concentrations of $\mathrm{Pt}$, the average distance of separation between the electrons and holes decreases, and the Pt clusters themselves can act as recombination centers. Choi et al. [38] also observed that there is an optimal metal 


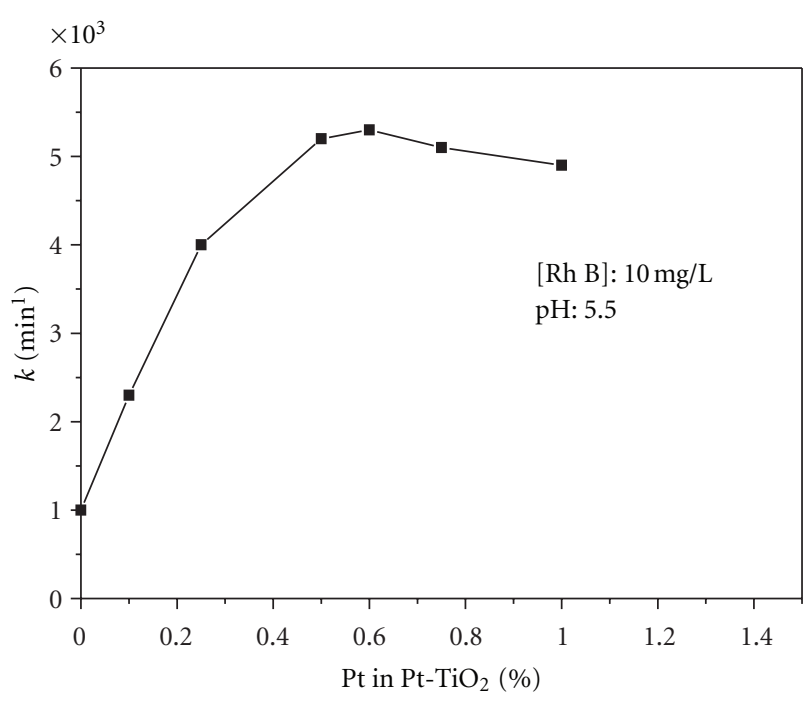

Figure 6: Effect of $\mathrm{Pt}$ concentration in $\mathrm{Pt} / \mathrm{TiO}_{2} / \mathrm{Tile}$ on the rate constant of Rhodamine $\mathrm{B}$ degradation under sunlight.

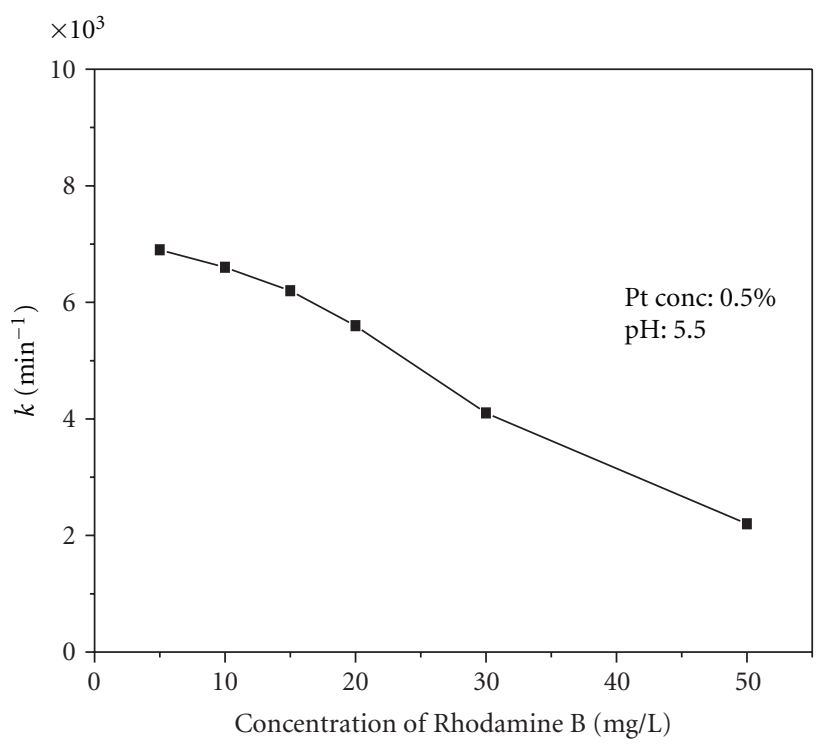

FIGURE 7: Effect of concentration of the Rhodamine B on its photocatalytic degradation in presence of $\mathrm{Pt} / \mathrm{TiO}_{2} / \mathrm{Tile}$ under sunlight.

dopant concentration above which the photocatalytic activity decreases.

Studies on the effect of concentration of the dye on the rate of photocatalytic degradation showed that the degradation decreased with increasing initial concentration. The results are plotted in Figure 7.

Since the degradation is accelerated by both catalyst and light, the negative effect of increasing concentration implies that at higher concentration, the dye is inhibiting the action of catalyst and/or light. At higher concentration, there will be stronger adsorption of the dye on the surface of the catalyst. This will inhibit the direct absorption of light by $\mathrm{Pt} / \mathrm{TiO}_{2}$, thereby affecting its ability to generate active radicals. In the

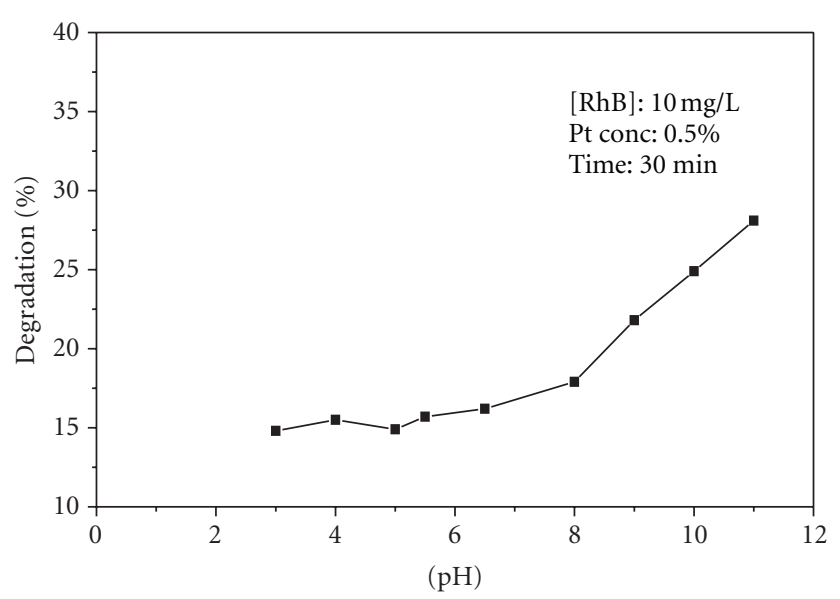

FIGURE 8: Effect of $\mathrm{pH}$ on the solar photocatalytic degradation of Rhodamine $\mathrm{B}$ in presence of $\mathrm{Pt} / \mathrm{TiO}_{2} /$ Tile.

absence of significant continued degradation, the adsorbed dye will not leave the surface sites, thus preventing the adsorption of new molecules and consequent degradation. Thus, the light absorption and number of adsorption sites are the two factors affected by higher concentration of the dye. It is also known that the dye itself will be absorbing more solar light at higher concentration. The path length of light entering the system also decreases with increase in concentration [39].

The $\mathrm{pH}$ is an important factor in the case of wastewater, and hence, its effect on the photocatalytic degradation of the dye in water is investigated. The degradation remains more or less the same in the range of 3-6.5 and increases thereafter. The results are shown in Figure 8.

The increased degradation at higher $\mathrm{pH}$ is not due to any change in the absorption of light as the $\lambda_{\mathrm{mx}}$ for the dye changes very little $(551-553 \mathrm{~nm})$ in the $\mathrm{pH}$ range of $1-13$ [40], even though Rhodamine exists in two principal forms in water, that is, cationic $\left(\mathrm{RhB}^{+}\right)$or in zwitterionic $\left(\mathrm{RhB}^{ \pm}\right)$. At $\mathrm{pH}$ value less than the point of zero charge $(\mathrm{PZC})$ of $\mathrm{TiO}_{2}$ (6.5), the surface will be positively charged. In the acidic range, the dye will be in cationic form $\left(\mathrm{RhB}^{+}\right)$. Hence, in this range, due to electrostatic repulsive forces, the adsorption of the dye on the catalyst is less. Thus, the surface-promoted degradation is less, and the observed degradation is primarily taking place in the solution. At higher $\mathrm{pH}$ value, the $\mathrm{RhB}^{+}$ gets deprotonated and its zwitterion is formed. This can get adsorbed onto the negatively charged catalyst surface resulting in increased degradation of the dye. Further, under alkaline conditions, more $\mathrm{OH}$ radical formation is possible from the abundant hydroxide ions, which also enhances the degradation.

3.3. Photocatalytic Disinfection of E. coli on $\mathrm{Pt} / \mathrm{TiO}_{2} /$ Tile. Heterogeneous photocatalysis has been found to be an effective method for the deactivation of bacteria in water [41]. Conventional semiconductors such as $\mathrm{ZnO}$ and $\mathrm{TiO}_{2}$ which are extensively investigated as photocatalysts can be activated only by UV light, which make them inefficient for solar 


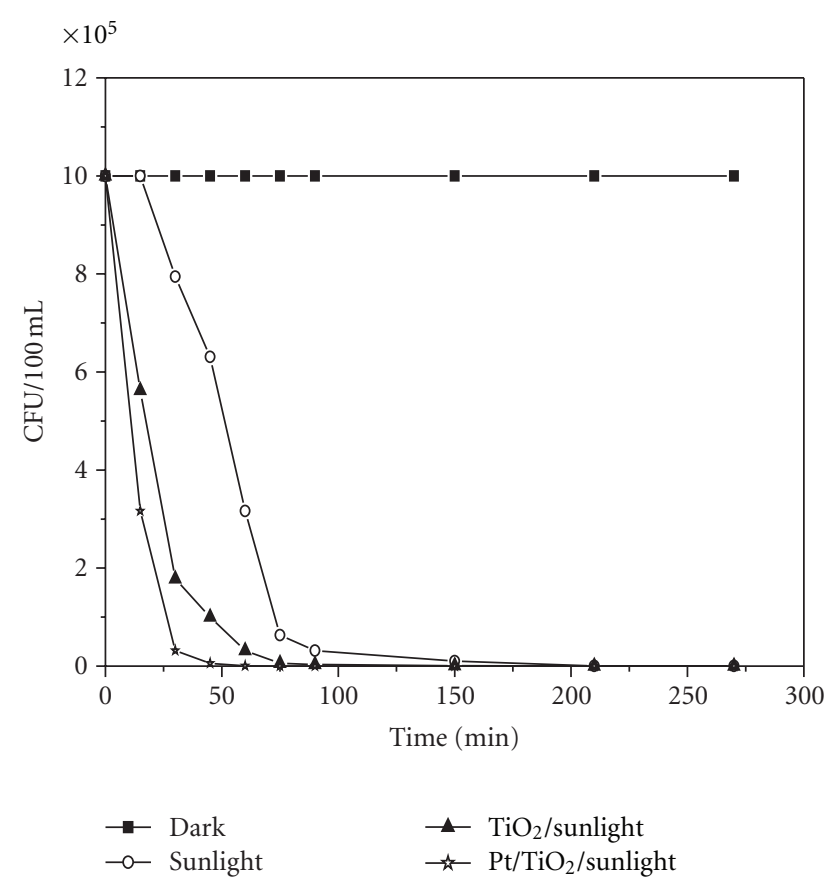

Figure 9: Solar deactivation of E. coli under different photocatalytic conditions.

energy application. Since $\mathrm{Pt} / \mathrm{TiO}_{2} /$ tile is effective for the removal of chemical pollutants in sunlight, the same is tested for the removal of $E$. coli from water.

Results presented in Figure 9 show that the bacteria remain practically unaffected in the dark. However, in presence of sunlight, the population is reduced gradually even in the absence of the catalyst. In the case of $\mathrm{Pt} / \mathrm{TiO}_{2} /$ tile, total inactivation takes place in 50 minutes, while it takes 90 minutes in the case of $\mathrm{TiO}_{2} /$ tile. In the absence of catalyst but in presence of light, there is an initial induction period during which the deactivation is negligible. This may be the reason why some of the earlier researchers [42] did not observe any inactivation of $E$. coli in the 60 minutes duration of their study. The deactivation is not due to temperature rise in presence of light as reported by Melian et al. [43] since in our case the temperature was maintained constant at $27 \pm 1^{\circ} \mathrm{C}$ by circulating water from a thermostat. Since the visible light induced deactivation is more in the presence of $\mathrm{Pt} / \mathrm{TiO}_{2} /$ tile compared to direct irradiation in the absence of any catalyst, it is clear that the catalyst plays a significant role in harnessing solar energy for bacterial decontamination. Comparative evaluation of the catalyst in immobilized form as well as in suspension showed that the suspension is more effective [44]. The number of surviving bacteria in the case of the $\mathrm{Pt} / \mathrm{TiO}_{2} /$ tile and the suspended catalyst under identical conditions at different time intervals show that the suspension is more effective throughout for bacteria removal.

The $\mathrm{pH}$ of natural waters and wastewater will normally be in the range of 5-9. Hence, the effect of $\mathrm{pH}$ on the deactivation of $E$. coli mediated by $\mathrm{Pt} / \mathrm{TiO}_{2}$ in presence of sunlight is examined. It is observed that $\mathrm{pH}$ has no significant effect on the rate of deactivation in this $\mathrm{pH}$ range.
The reason often cited for the convenience of chemical decontamination over other techniques such as photocatalysis is that in the former, the destruction of microorganisms is complete, and hence, the reemergence is not significant. To compare the efficacy of chemical treatment with photocatalysis, the reemergence of $E$. coli in water treated with $\mathrm{TiO}_{2}$ /tile/light, $\mathrm{Pt} / \mathrm{TiO}_{2}$ /tile/light, and light alone is examined. After complete inactivation of the bacteria, in experiments with and without catalyst, the reemergence was tested after 2, 24, and $48 \mathrm{hr}$. There was no bacterial presence detected in any of the systems after $2 \mathrm{hr}$. However, significant reemergence was noticed after $24 \mathrm{hr}$ in the light alone system. The reemergence was much slower in the system with catalyst, the comparative rate of reemergence being in the order $\mathrm{TiO}_{2} /$ tile/light $\gg \mathrm{Pt} / \mathrm{TiO}_{2} /$ tile/light. This indicates that the destruction in presence of the catalyst $\mathrm{Pt} / \mathrm{TiO}_{2}$ is almost as irreversible as in the case of chemical decontamination, while the sunlight alone may not be sufficient for complete destruction.

The mechanism of deactivation of $E$. coli is not known clearly yet. Free radicals have an adverse effect on cell DNA replication and the modification of cellular membrane. Cho et al. [45] demonstrated linear correlation between ${ }^{\circ} \mathrm{OH}$ concentration and E. coli inactivation. Direct photocatalytic oxidation of intracellular coenzyme is also proposed by some authors [42]. The $\mathrm{H}_{2} \mathrm{O}_{2}$ formed in the system also is a good bactericide $[44,46]$. Higher concentration of $\mathrm{OH}$ and $\mathrm{H}_{2} \mathrm{O}_{2}$ in presence of catalyst will lead to higher irreversible destruction of the bacteria. Exposure to reactive oxygen species such as $\mathrm{O}_{2}{ }^{-\bullet}$ and ${ }^{\bullet} \mathrm{OH}$ generated during photocatalysis can result in oxidative damage to cellular components, DNA and RNA [47-49]. The disruption of cell membrane is attributed to peroxidation of the unsaturated phospholipids leading to loss of respiratory activity [50, 51]. Subsequent loss of fluidity and increased ion permeability permit oxidative attack of internal cellular components resulting in cell death.

\section{Conclusion}

Deposition of noble metal $\mathrm{Pt}$ on $\mathrm{TiO}_{2}$ extends the light absorption of the latter from UV to the visible range which makes the composite a good photocatalyst for solar decontamination of polluted water. In this study, $\mathrm{Pt} / \mathrm{TiO}_{2}$ is immobilized by coating on an ordinary ceramic tile, and its photocatalytic activity is tested for the removal of a chemical pollutant, Rhodamine B, and a bacterial pollutant, E. coli. $\mathrm{Pt} / \mathrm{TiO}_{2}$ is more effective than $\mathrm{TiO}_{2}$ alone for the removal of both types of pollutants. The catalyst is characterized by XRD, DRS, SEM, and EDAX. Higher $\mathrm{pH}$ favours the removal of Rhodamine $\mathrm{B}$, while increase in concentration of the dye decreases the rate of removal. There is an optimal concentration of $\mathrm{Pt}$ beyond which the rate of enhancement decreases. Suspension system is more efficient compared to the immobilized catalyst. However, problems associated with the separation of the catalyst make the latter more promising for field application. The bacterial contaminant E. coli can be removed by light even in the absence of the catalyst. However, the presence of catalyst accelerates the decontamination significantly. Also, the reemergence of the bacteria after 
the light is off is inhibited to a great extent by the catalysts. A tentative mechanism for the chemical and bacterial decontamination is proposed and discussed.

\section{Acknowledgments}

Financial support from the Department of Science and Technology (DST), Government of India to one of the authors (S. P. Devipriya) under the WOS-A scheme is gratefully acknowledged.

\section{References}

[1] R. W. Matthews, "Photocatalytic oxidation of organic contaminants in water: an aid to environmental preservation," Pure and Applied Chemistry, vol. 64, pp. 1285-1290, 1992.

[2] S. Devipriya and S. Yesodharan, "Photocatalytic degradation of pesticide contaminants in water," Solar Energy Materials and Solar Cells, vol. 86, no. 3, pp. 309-348, 2005.

[3] M. Muneer and C. Boxall, "Photocatalysed degradation of a pesticide derivative glyphosate in aqueous suspensions of titanium dioxide," International Journal of Photoenergy, vol. 2008, Article ID 197346, 7 pages, 2008.

[4] P. A. Deshpande and G. Madras, "Photocatalytic degradation of phenol by base metal-substituted orthovanadates," Chemical Engineering Journal, vol. 161, no. 1-2, pp. 136-145, 2010.

[5] D. Ollis, P. Pichat, and N. Serpone, " $\mathrm{TiO}_{2}$ photocatalysis-25 years," Applied Catalysis B, vol. 99, no. 3-4, p. 377, 2010.

[6] J. Moon, C. Y. Yun, K. W. Chung, M. S. Kang, and J. Yi, "Photocatalytic activation of $\mathrm{TiO}_{2}$ under visible light using Acid Red 44," Catalysis Today, vol. 87, no. 1-4, pp. 77-86, 2003.

[7] D. Pei and J. Luan, "Development of visible light-responsive sensitized photocatalysts," International Journal of Photoenergy, vol. 2012, Article ID 262831, 13 pages, 2012.

[8] S. Kim and W. Choi, "Visible-light-induced photocatalytic degradation of 4-chlorophenol and phenolic compounds in aqueous suspension of pure titania: demonstrating the existence of a surface-complex-mediated path," Journal of Physical Chemistry B, vol. 109, no. 11, pp. 5143-5149, 2005.

[9] H. Chen, W. Li, H. Liu, and L. Zhu, "Performance enhancement of CdS-sensitized $\mathrm{TiO}_{2}$ mesoporous electrode with two different sizes of CdS nanoparticles," Microporous and Mesoporous Materials, vol. 138, no. 1-3, pp. 235-238, 2011.

[10] M. M. Rahman, K. M. Krishna, T. Soga, T. Jimbo, and M. Umeno, "Optical properties and X-ray photoelectron spectroscopic study of pure and $\mathrm{Pb}$-doped $\mathrm{TiO}_{2}$ thin films," Journal of Physics and Chemistry of Solids, vol. 60, no. 2, pp. 201-210, 1999.

[11] C. G. Wu, C. C. Chao, and F. T. Kuo, "Enhancement of the photo catalytic performance of $\mathrm{TiO}_{2}$ catalysts via transition metal modification," Catalysis Today, vol. 97, no. 2-3, pp. 103112,2004

[12] E. Bae and W. Choi, "Highly enhanced photoreductive degradation of perchlorinated compounds on dye-sensitized metal/ $\mathrm{TiO}_{2}$ under visible light," Environmental Science and Technology, vol. 37, no. 1, pp. 147-152, 2003.

[13] Y. Pellegrin, L. Le Pleux, E. Blart et al., "Ruthenium polypyridine complexes as sensitisers in $\mathrm{NiO}$ based p-type dyesensitized solar cells: effects of the anchoring groups," Journal of Photochemistry and Photobiology A, vol. 219, no. 2, pp. 235242, 2011.

[14] W. J. Youngblood, S. H. Anna Lee, K. Maeda, and T. E. Mallouk, "Visible light water splitting using dye-sensitized oxide semiconductors," Accounts of Chemical Research, vol. 42, no. 12, pp. 1966-1973, 2009.

[15] S. Sakthivel, B. Neppolian, M. V. Shankar, B. Arabindoo, M. Palanichamy, and V. Murugesan, "Solar photocatalytic degradation of azo dye: comparison of photocatalytic efficiency of $\mathrm{ZnO}$ and $\mathrm{TiO}_{2}$," Solar Energy Materials and Solar Cells, vol. 77, no. 1, pp. 65-82, 2003.

[16] Y. Xu, W. Zheng, and W. Liu, "Enhanced photocatalytic activity of supported $\mathrm{TiO}_{2}$ : dispersing effect of $\mathrm{SiO}_{2}$," Journal of Photochemistry and Photobiology A, vol. 122, no. 1, pp. 5760, 1999.

[17] H. Tada, A. Hattori, Y. Tokihisa, K. Imai, N. Tohge, and S. Ito, "A patterned- $\mathrm{TiO}_{2} / \mathrm{SnO}_{2}$ bilayer type photocatalyst," Journal of Physical Chemistry B, vol. 104, no. 19, pp. 4585-4587, 2000.

[18] Y. Li, S. Sun, M. Ma, Y. Ouyang, and W. Yan, "Kinetic study and model of the photocatalytic degradation of rhodamine $\mathrm{B}$ $(\mathrm{RhB})$ by a $\mathrm{TiO}_{2}$-coated activated carbon catalyst: effects of initial $\mathrm{RhB}$ content, light intensity and $\mathrm{TiO}_{2}$ content in the catalyst," Chemical Engineering Journal, vol. 142, no. 2, pp. 147-155, 2008.

[19] H. Uchida, S. Itoh, and H. Yoneyama, "Photocatalytic decomposition of propyzamide using $\mathrm{TiO}_{2}$ supported on activated carbon," Chemistry Letters, vol. 22, pp. 1995-1998, 1993.

[20] D. K. Lee, S. C. Kim, I. C. Cho, S. J. Kim, and S. W. Kim, "Photocatalytic oxidation of microcystin-LR in a fluidized bed reactor having $\mathrm{TiO}_{2}$-coated activated carbon," Separation and Purification Technology, vol. 34, no. 1-3, pp. 59-66, 2004.

[21] D. K. Lee, S. C. Kim, S. J. Kim, I. S. Chung, and S. W. Kim, "Photocatalytic oxidation of microcystin-LR with $\mathrm{TiO}_{2}$ coated activated carbon," Chemical Engineering Journal, vol. 102, no. 1, pp. 93-98, 2004.

[22] X. Z. Li and F. B. Li, "Study of $\mathrm{Au} / \mathrm{Au}^{3+}-\mathrm{TiO}_{2}$ photocatalysts toward visible photooxidation for water and wastewater treatment," Environmental Science and Technology, vol. 35, no. 11, pp. 2381-2387, 2001.

[23] S. Sakthivel, M. V. Shankar, M. Palanichamy, B. Arabindoo, D. W. Bahnemann, and V. Murugesan, "Enhancement of photocatalytic activity by metal deposition: Characterisation and photonic efficiency of Pt, $\mathrm{Au}$ and Pd deposited on $\mathrm{TiO}_{2}$ catalyst," Water Research, vol. 38, no. 13, pp. 3001-3008, 2004.

[24] V. M. Mendez-Florez, D. Friedmann, and D. W. Bahnemann, "Durability of $\mathrm{Ag}-\mathrm{TiO}_{2}$ photocatalysts assessed for the degradation of dichloroacetic acid," International Journal of Photoenergy, vol. 2008, Article ID 280513, 11 pages, 2008.

[25] F. B. Li and X. Z. Li, "The enhancement of photodegradation efficiency using $\mathrm{Pt}-\mathrm{TiO}_{2}$ catalyst," Chemosphere, vol. 48, no. 10, pp. 1103-1111, 2002.

[26] H. W. Chen, Y. Ku, and Y. L. Kuo, "Effect of Pt/TiO 2 characteristics on temporal behavior of o-cresol decomposition by visible light-induced photocatalysis," Water Research, vol. 41, no. 10, pp. 2069-2078, 2007.

[27] J. M. Herrmann, J. Disdier, and P. Pichat, "Photoassisted platinum deposition on $\mathrm{TiO}_{2}$ powder using various platinum complexes," Journal of Physical Chemistry, vol. 90, no. 22, pp. 6028-6034, 1986.

[28] Z. Zheng, B. Huang, X. Qin, X. Zhang, Y. Dai, and M. H. Whangbo, "Facile in situ synthesis of visible-light plasmonic photocatalysts ${\mathrm{M} @ \mathrm{TiO}_{2}}_{2}(\mathrm{M}=\mathrm{Au}, \mathrm{Pt}, \mathrm{Ag})$ and evaluation of their photocatalytic oxidation of benzene to phenol," Journal of Materials Chemistry, vol. 21, no. 25, pp. 9079-9087, 2011.

[29] P. V. Kamat, "Photophysical, photochemical and photocatalytic aspects of metal nanoparticles," Journal of Physical Chemistry B, vol. 106, no. 32, pp. 7729-7744, 2002. 
[30] S. Eustis and M. A. El-Sayed, "Why gold nanoparticles are more precious than pretty gold: Noble metal surface plasmon resonance and its enhancement of the radiative and nonradiative properties of nanocrystals of different shapes," Chemical Society Reviews, vol. 35, no. 3, pp. 209-217, 2006.

[31] H. Zhu, X. Chen, Z. Zheng et al., "Mechanism of supported gold nanoparticles as photocatalysts under ultraviolet and visible light irradiation," Chemical Communications, no. 48, pp. 7524-7526, 2009.

[32] X. Chen, Z. Zheng, X. Ke et al., "Supported silver nanoparticles as photocatalysts under ultraviolet and visible light irradiation," Green Chemistry, vol. 12, no. 3, pp. 414-419, 2010.

[33] P. Wang, B. Huang, X. Qin et al., “Ag@AgCl: a highly efficient and stable photocatalyst active under visible light," Angewandte Chemie - International Edition, vol. 47, no. 41, pp. 7931-7933, 2008.

[34] P. Wang, B. Huang, X. Qin, X. Zhang, Y. Dai, and M. $\mathrm{H}$. Whangbo, "Ag/AgBr$/ \mathrm{WO}_{3} \cdot \mathrm{H}_{2} \mathrm{O}$ : visible-light photocatalyst for bacteria destruction," Inorganic Chemistry, vol. 48, no. 22, pp. 10697-10702, 2009.

[35] S. G. Anju, S. Yesodharan, and E. P. Yesodharan, "Sonophotocatalytic degradation of phenol over semiconductor oxides," Chemical Engineering Journal, vol. 189-190, no. 1, pp. 84-93, 2012.

[36] S. Anandan, P. Sathish Kumar, N. Pugazhenthiran, J. Madhavan, and P. Maruthamuthu, "Effect of loaded silver nanoparticles on $\mathrm{TiO}_{2}$ for photocatalytic degradation of Acid Red 88," Solar Energy Materials and Solar Cells, vol. 92, no. 8, pp. 929937, 2008.

[37] H. Gerischer, "Photodecomposition of semiconductors," Berichte der Bunsengesellschaft für physikalische Chemie, vol. 77, pp. 771-779, 1973.

[38] W. Choi, A. Termin, and M. R. Hoffmann, "The role of metal ion dopants in quantum-sized $\mathrm{TiO}_{2}$ : correlation between photoreactivity and charge carrier recombination dynamics," Journal of Physical Chemistry, vol. 98, no. 51, pp. 13669-13679, 1994.

[39] L. You-Ji and C. Wei, "Photocatalytic degradation of Rhodamine $\mathrm{B}$ using nanocrystalline $\mathrm{TiO}_{2}$-zeolite surface composite catalysts: effects of photocatalytic condition on degradation efficiency," Catalysis Science and Technology, vol. 1, no. 5, pp. 802-809, 2011.

[40] S. Merouani, O. Hamdaoui, F. Saoudi, and M. Chiha, "Sonochemical degradation of Rhodamine B in aqueous phase: effects of additives," Chemical Engineering Journal, vol. 158, no. 3, pp. 550-557, 2010.

[41] A. Mills and S. Le Hunte, "An overview of semiconductor photocatalysis," Journal of Photochemistry and Photobiology A, vol. 108, no. 1, pp. 1-35, 1997.

[42] C. Wei, W. Y. Lin, Z. Zainal et al., "Bactericidal activity of $\mathrm{TiO}_{2}$ photocatalyst in aqueous media: toward a solar-assisted water disinfection system," Environmental Science and Technology, vol. 28, no. 5, pp. 934-938, 1994.

[43] J. A. H. Melian, J. M. D. Rodriguez, A. V. Suarez et al., "The photocatalytic disinfection of urban wastewaters," Chemosphere, vol. 41, pp. 323-327, 2000.

[44] S. P. Devipriya, R. Kanjur, and S. Yesodharan, "Inactivation of Escherichia coli in water using $\mathrm{TiO}_{2}$ as photocatalyst," Pollution Research, vol. 24, no. 1, pp. 87-91, 2005.

[45] M. Cho, H. Chung, W. Choi, and J. Yoon, "Linear correlation between inactivation of $\mathrm{E}$. coli and $\mathrm{OH}$ radical concentration in $\mathrm{TiO}_{2}$ photocatalytic disinfection," Water Research, vol. 38, no. 4, pp. 1069-1077, 2004.
[46] M. R. Hoffmann, S. T. Martin, W. Choi, and D. W. Bahnemann, "Environmental applications of semiconductor photocatalysis," Chemical Reviews, vol. 95, no. 1, pp. 69-96, 1995.

[47] Z. Huang, P. C. Maness, D. M. Blake, E. J. Wolfrum, S. L. Smolinski, and W. A. Jacoby, "Bactericidal mode of titanium dioxide photocatalysis," Journal of Photochemistry and Photobiology A, vol. 130, no. 2-3, pp. 163-170, 2000.

[48] A. Erkan, U. Bakir, and G. Karakas, "Photocatalytic microbial inactivation over Pd doped $\mathrm{SnO} 2$ and $\mathrm{TiO}_{2}$ thin films," Journal of Photochemistry and Photobiology A, vol. 184, no. 3, pp. 313321, 2006.

[49] D. M. Blake, P. C. Maness, Z. Huang, E. J. Wolfrum, J. Huang, and W. A. Jacoby, "Application of the photocatalytic chemistry of titanium dioxide to disinfection and the killing of cancer cells," Separation and Purification Methods, vol. 28, no. 1, pp. $1-50,1999$.

[50] A. G. Rincón, C. Pulgarin, N. Adler, and P. Peringer, "Interaction between E. coli inactivation and DBP-precursorsdihydroxybenzene isomers - in the photocatalytic process of drinking-water disinfection with $\mathrm{TiO}_{2}$," Journal of Photochemistry and Photobiology A, vol. 139, no. 2-3, pp. 233-241, 2001.

[51] A. G. Rincón and C. Pulgarin, "Field solar E. coli inactivation in the absence and presence of $\mathrm{TiO}_{2}$ : is UV solar dose an appropriate parameter for standardization of water solar disinfection?" Solar Energy, vol. 77, no. 5, pp. 635-648, 2004. 


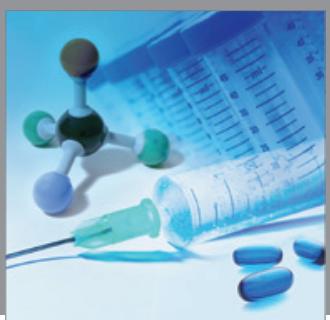

International Journal of

Medicinal Chemistry

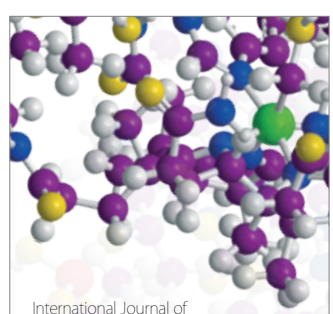

Carbohydrate Chemistry

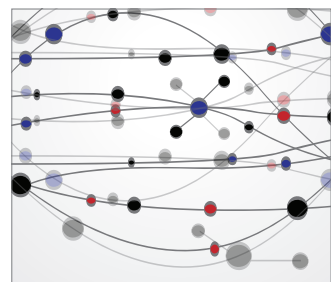

The Scientific World Journal
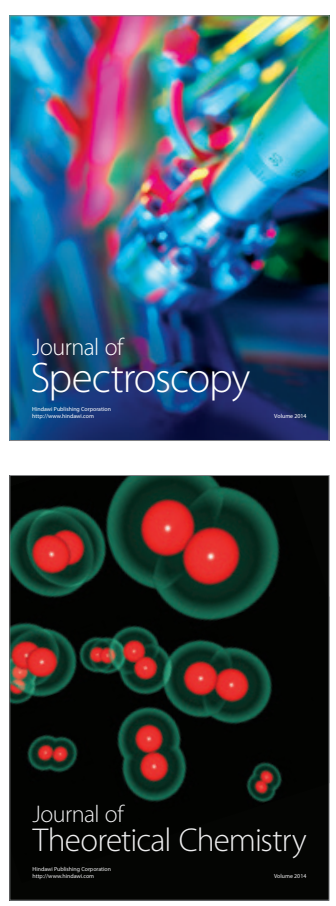
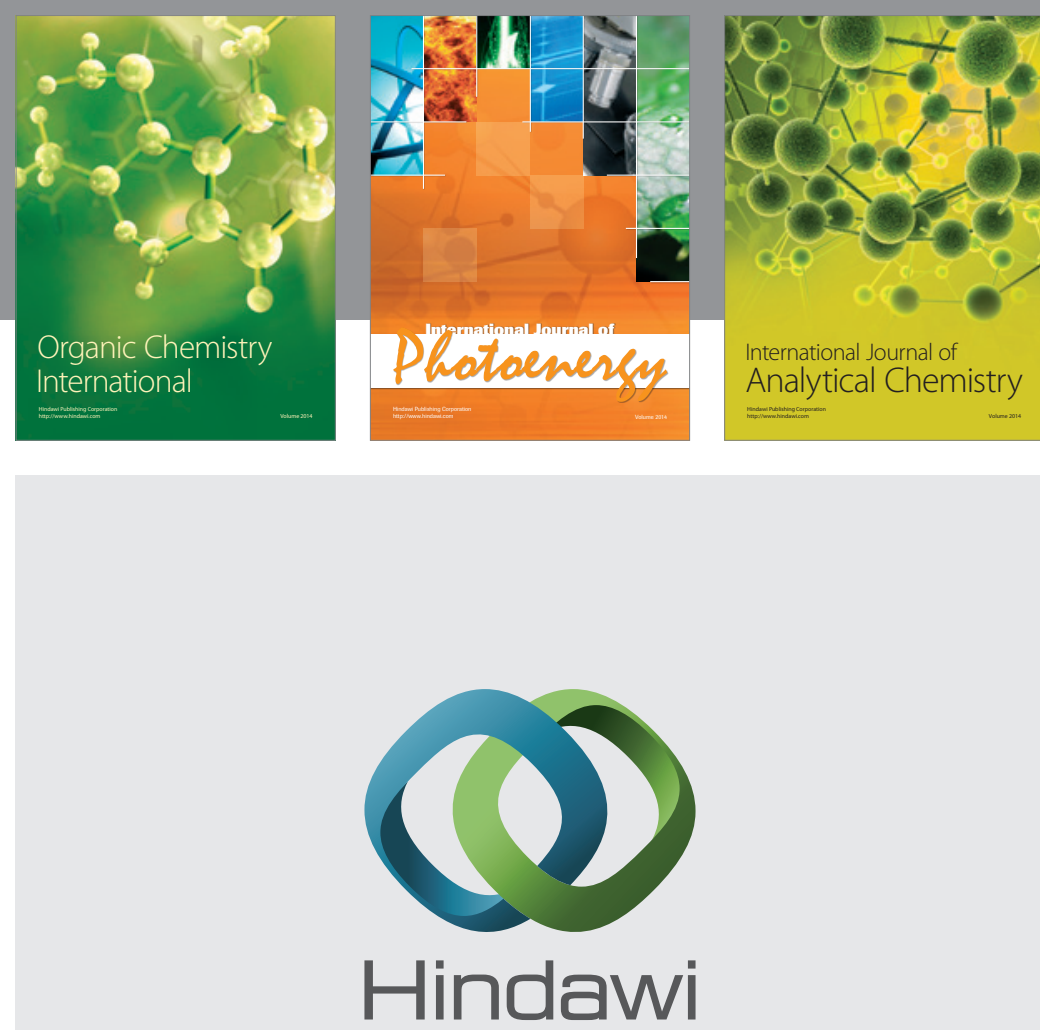

Submit your manuscripts at

http://www.hindawi.com
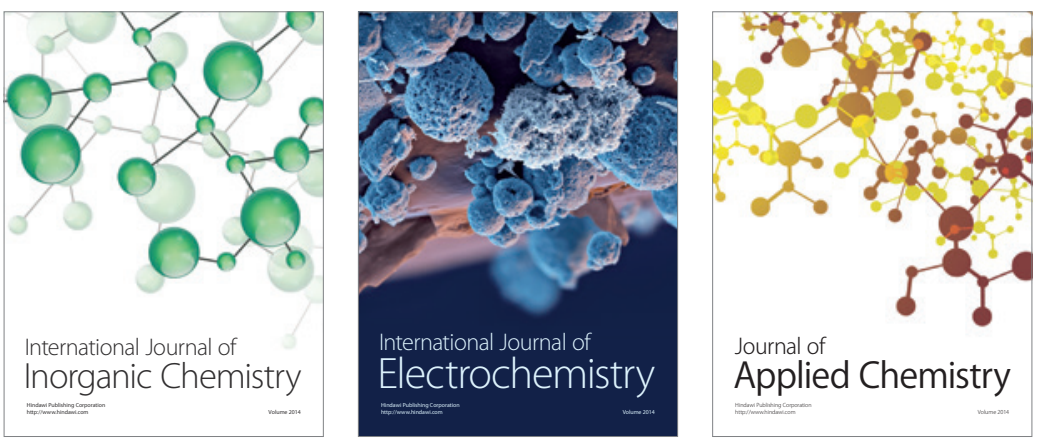

Journal of

Applied Chemistry
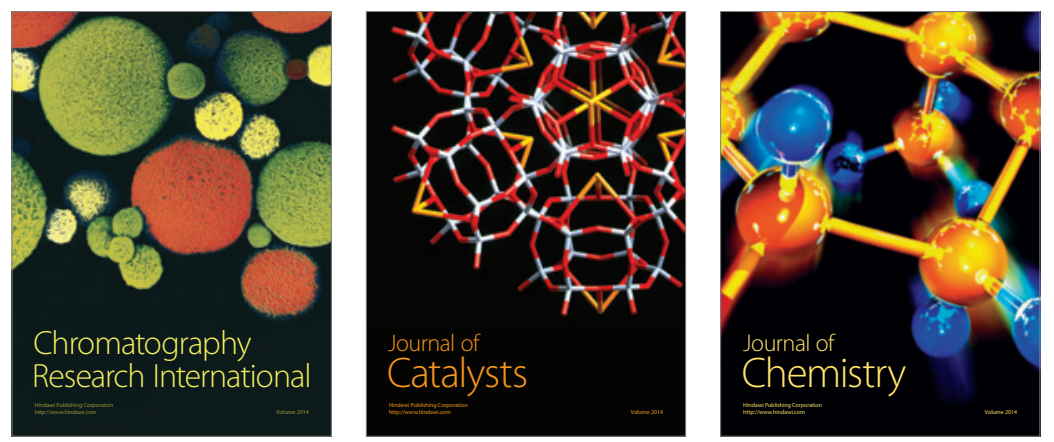
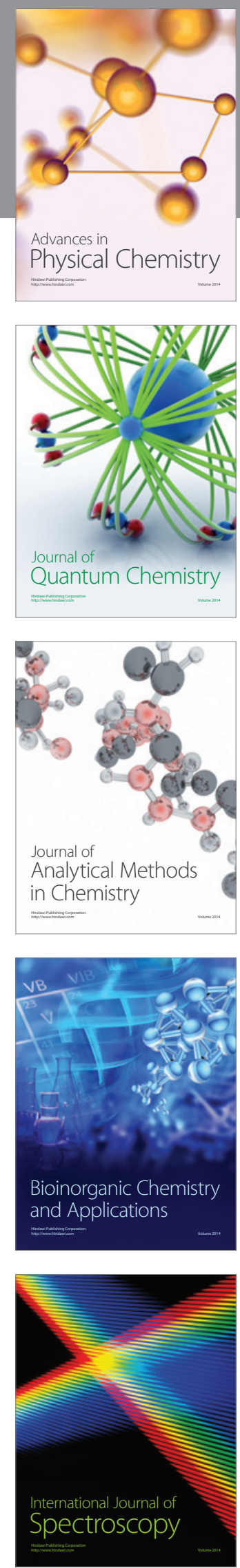